\title{
Influence of a New Tap Drill Geometry on C45 (1.0503) Steel Processing
}

\author{
Adrian Sorin FAUR, Marcel Sabin POPA, Stefan SATTEL, Florin MILAS
}

\begin{abstract}
The article presents the research of a cutting tap that has a geometry that extends the cutting tool's life by reducing chipping when the tap reverses while still engaged in cutting a thread. It relates to the improvement of a spiral tap which discharges chips toward a shank via a helical flute. The article contains details about the tap geometries and the results obtained in this research, such as: tool life, chips comparison after cutting 1000 threads, surface comparison after processing 1000 threads and torsion moment analysis. Chip removal is an important factor in the process of threading blind holes which influences the life of the tool.
\end{abstract}

Keywords: chips analysis; tap geometries; tapping problems; thread analysis

\section{INTRODUCTION}

Material removal rate is the main factor that defines a highly optimised performant cutting process. This is calculated using a mathematical formula based on the chip section and cutting speed. Constant improvement and higher productivity in the machining industry are due to the competitive side of companies. By improving the material removal rate and cutting speed, the thermal and mechanical stress that appears during the cutting process increases. The cutting forces and temperatures are high during machining on the cutting edge, especially on the tools outer corner which wears out the most because of the limited effective cooling. That is a very important factor that needs to be taken into consideration during machining because it helps avoid diffusion and abrasive wear of the cutting tool [1].

It is estimated that around $15 \%$ of mechanical components worldwide are made using machining processes, therefore metal processing is important to the manufacturing technology [2].

Machining using taps involves axial and rotational movement usually done by the cutting tool when tapping the workpiece but sometimes the workpiece is rotated and the tapping tool performs the axial movement.

The cutting tool feed with every rotation must be the same as the pitch of the desired thread. Due to the fact that the tapping process takes place inside a hole, it is difficult to determine the cause and solution to problems when these appear even though chip formation and removal provide some answers. Tap design and accuracy are vital to a successful tapped hole. Inadequate part design, insufficient lubrication, machine feed variations and tap retraction are all potential factors that can cause problems during the cutting process [3]

Tapping process is one of the most demanding machining tasks in production engineering. Moreover, the threads are often not made until the end of the production chain, which requires a high level of process reliability. Yet, in mass production, manufacturers demand that the threads should be produced even more cost-effective and in a timely manner. In this context, the continuous, ongoing development of processes and of drilling and threading tools is needed [4].

Tapping is the most commonly used procedure for making internal threads. At the base of development of cutting tools stays the macro/micro geometry and the coatings for high quality and lower production costs per thread [5].

The aim of this work is the optimisation of the cutting tool geometry. The tap geometry is very important for the tool's life, influencing the forces that act upon the tap during the cutting process as well as the way the chips are removed. Chip removal is an important factor in the process of threading blind holes, as clusters of chips can occur, which can further lead to tool failure.

The research aims to determine the optimal geometry of the tap, knowing the material the tool is built of. The experiments were conducted in Carbon-Steel $(\mathrm{C} 45 / 1.0503)$. The elements which are intended to be improved are the forces that occur during processing.

These forces are very important concerning to the phenomenon of spontaneous tool breaking or to the sudden evolution wear and tear.

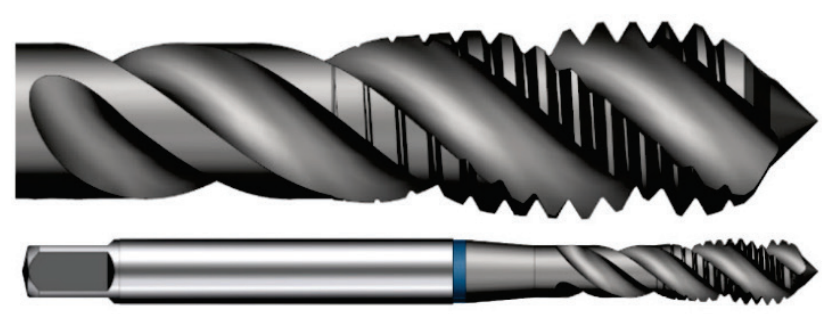

Figure 1 Helical tap [6]

This article will focus on helical taps for threading blind holes, like the one in Fig. 1.

Factors that have a major influence on threading, are: - A smaller rake angle:

A smaller rake angle increases the stability of cutting edges, cutting forces, cutting torque, and the tendency to compress the machined material (it cuts less with the main cutting edge and thus produces some slightly tighter threads). This produces weaker quality surfaces in the workpiece, making it more difficult to process harder materials.

- Spiral point angle:

The angle of the spiral cone is limited by the length of the attack cone and the number of flutes because the angle of the larger attack cone decreases the land width of the tooth. This causes a decrease in the cutting edge stability (increases the risk of breakage in the attack cone area). If the angle of the spiral attack cone is too low, chipping can 
become problematic. The remedy may come from lefthand helical tools.

- A larger helix angle:

A larger helix angle results in better chip removal but reduces teeth stability and cutting tool durability. Due to this, the stability of the tool decreases and this limits the maximum cutting torque.

- Flank clearance angle:

The angle of the flange should be adapted to the material being processed. Materials with higher tensile strength require a higher clearance angle on flank. With the increase of this angle, it decreases the tool guidance properties, which is why it is possible to produce cracks in soft material in case of using compensated Synchro chuck [5].

\section{TAP GEOMETRIES}

\subsection{The Tap with the Reduced Outside Diameter}

The first version proposed is one in which the outside diameter of the M8 standard tap is reduced. According to the operating principle of the tap, its forces and diameter cause the generation of a moment of torque, which often is the main factor that leads to tools breaking. By reducing the tap diameter, the arm strength shrinks but, more importantly, it decreases the amount of removed material (pre-drilling being carried out by the same drills), thus resulting in power torque moments. The standard tap overlapped with the tap with the reduced diameter is presented in Fig. 2 [9].

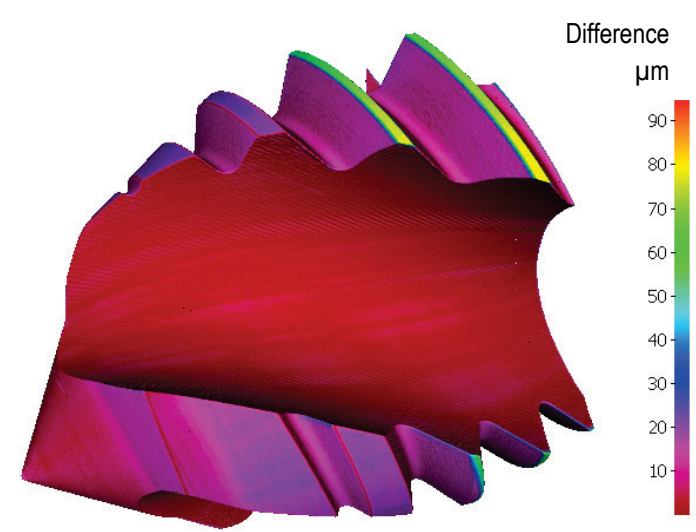

Figure 2 Standard tap overlapped with the exterior diameter reduced tap [9]

This overlapping was performed using the Alicona Infinite Focus measuring device. Infinite Focus is a highly accurate, extremely fast and highly flexible optical 3D measurement system. Users benefit from a 3D micro coordinate measurement machine and surface roughness measurement device in only one system. The range of measurable surfaces is almost unlimited, enabled by the use of coaxial lighting and an optimized LED ring light. In addition, all axes of Infinite Focus are equipped with highly accurate encoders ensuring highly precise stage movement. Users achieve traceable measurements that combine high resolution, high repeatability and high accuracy [7].

\subsection{The Tap with Double Flute}

This new geometric variant maintains the outside diameter reduced compared to the standard tap, adding a double flute (see Fig. 3). The role of this double flute is to carry out the chip through the discharge channel without having to stay glued to the guiding surface. Basically, it is intended to create a threshold of faster detachment of the chips from the tap guiding face.

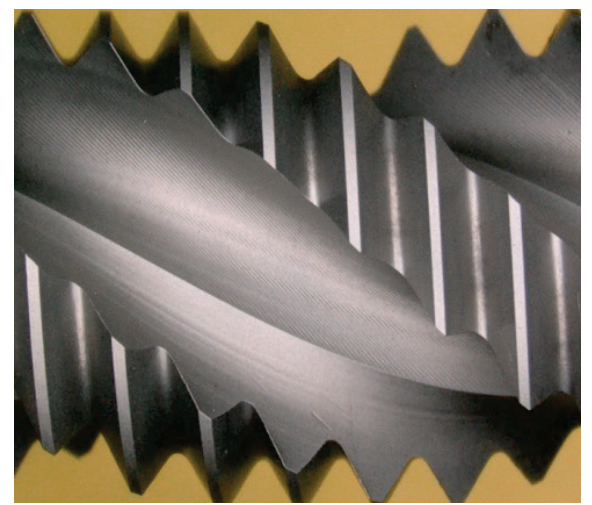

Figure 3 The tap with double flute

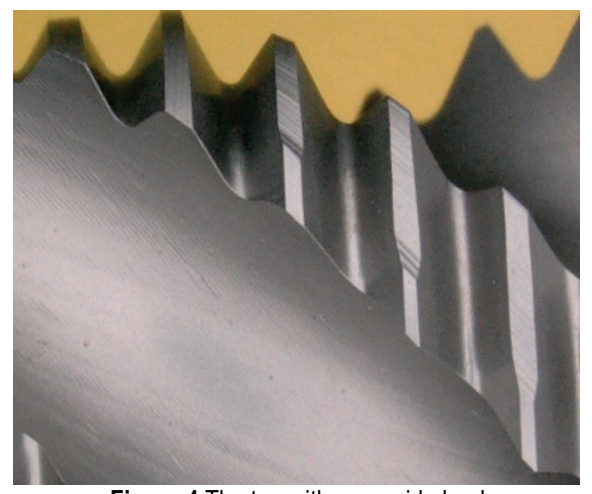

Figure 4 The tap with one guide land

\subsection{The Tap with One Guided Land}

The guided land is carried out on the contact surface of the tap, as presented in Fig. 4, this being intended to reduce friction with the workpiece when withdrawing the tool from the threaded hole. Compared to the standard tap, this geometric variant has a reduced outside diameter, it has no external relief but it doubled relief on teeth flanks. The constructive version aimed at reducing, as much as possible, the force generated during processing due to friction with the material [9].

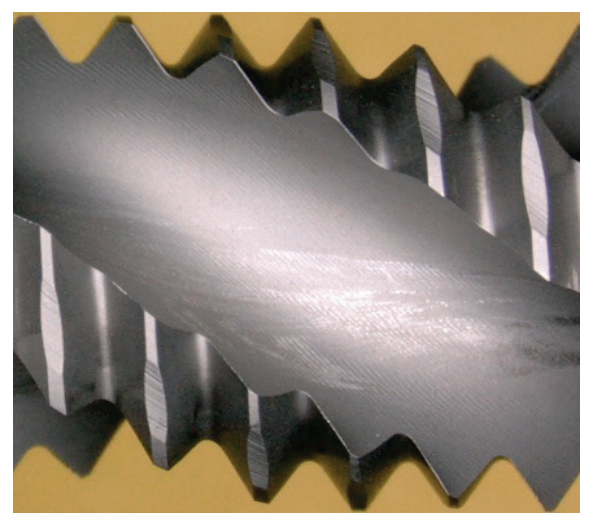

Figure $\mathbf{5}$ The tap with two guide lands 


\subsection{The Tap with Two Guide Lands}

The two guided lands tap shares the constructive principles of the one guided land tap variant but does not allow the driving and "galling" of the chip between the front teeth and the processed material while withdrawing the tap. This geometry tap is presented in Fig. 5 [9].

\subsection{The Tap with Increased Core Diameter}

The geometrical version with increased core diameter also has the exterior diameter reduced comparing with the standard tap. The ascending core serves to deflect the chips without remaining stuck on the guiding surface. The standard tap overlapped with the tap with increased core diameter is presented in Fig. 6. From this figure can be seen the partial growth of the core and the reduced exterior diameter as well. With standard taps, chips obtained after processing of stainless steel, tend to adhere to the surface of the guide land. The increased core directs the chips outwards, so after the withdrawal of the tap, the centrifugal force determines the chip to detach off the tap [9].

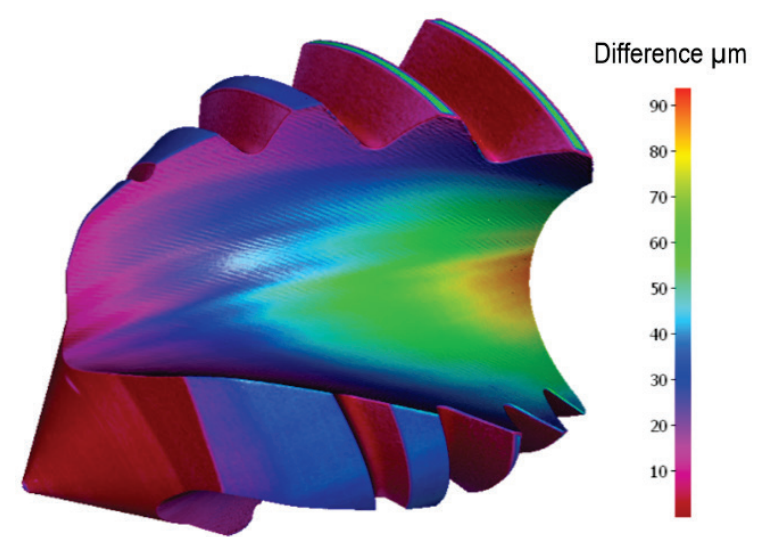

Figure 6 The standard tap overlapped with the tap with increased core diameter [9]

\section{EXPERIMENTAL METHODS 3.1 Tapping Test}

The workpiece material was Medium-Carbon-Steel $(\mathrm{C} 45 / 1.0503)$ in the form of a rectangular block of $30 \times 200 \times 500 \mathrm{~mm}$. The test was conducted with the machining centre DMU 65 MONOBLOCK with a Spike tool holder that allows us to measure the torsion moment and a Synchro chuck with compensation.

Synchro chucks, also called threading adapters have the benefit of compensating both axial and radial forces. Using these tool holders significantly increases the durability of the cutting tool in the thread processing $[5,9]$.

The threading was performed with external cooling. The most widespread method is the external supply of coolant, being used in most cases. This becomes problematic in processing deep threads with a horizontal position of the shaft, the coolant cannot always penetrate to the cutting edge [5].

The taps have standard coating and the same cutting parameters $\left(v_{\mathrm{c}}=12 \mathrm{~m} / \mathrm{min} ; 1,25 \mathrm{pitch} ; 3 \times D\right.$ depth, coolant concentration 12\%). All the taps have been measured before testing in order to check the geometry. In order to obtain reliable results, two taps were tested for each geometry, with a third one being tested where large differences were observed. During testing, at a certain interval of threads 3D scans on Alicona Infinite Focus, force measuring with Spike tool, pictures of tap, chips and threads were conducted. The durability of taps with different geometries is presented in Fig. 7.

By reducing the outside diameter of the tool, a major increase for the tool's life (approximately 20\%) can be observed. By adding an increased core diameter for the tap with reduced diameter, the tool life is increased by approximately $30 \%$. By adding two guide lands, doubled relief on flanks, no outside relief and reduced outside diameter leads to a substantial increase of the tool life (approximately 40\%) compared to the standard tap. The tap with double flute and reduced outside diameter has no major influence on the tool's life [9].

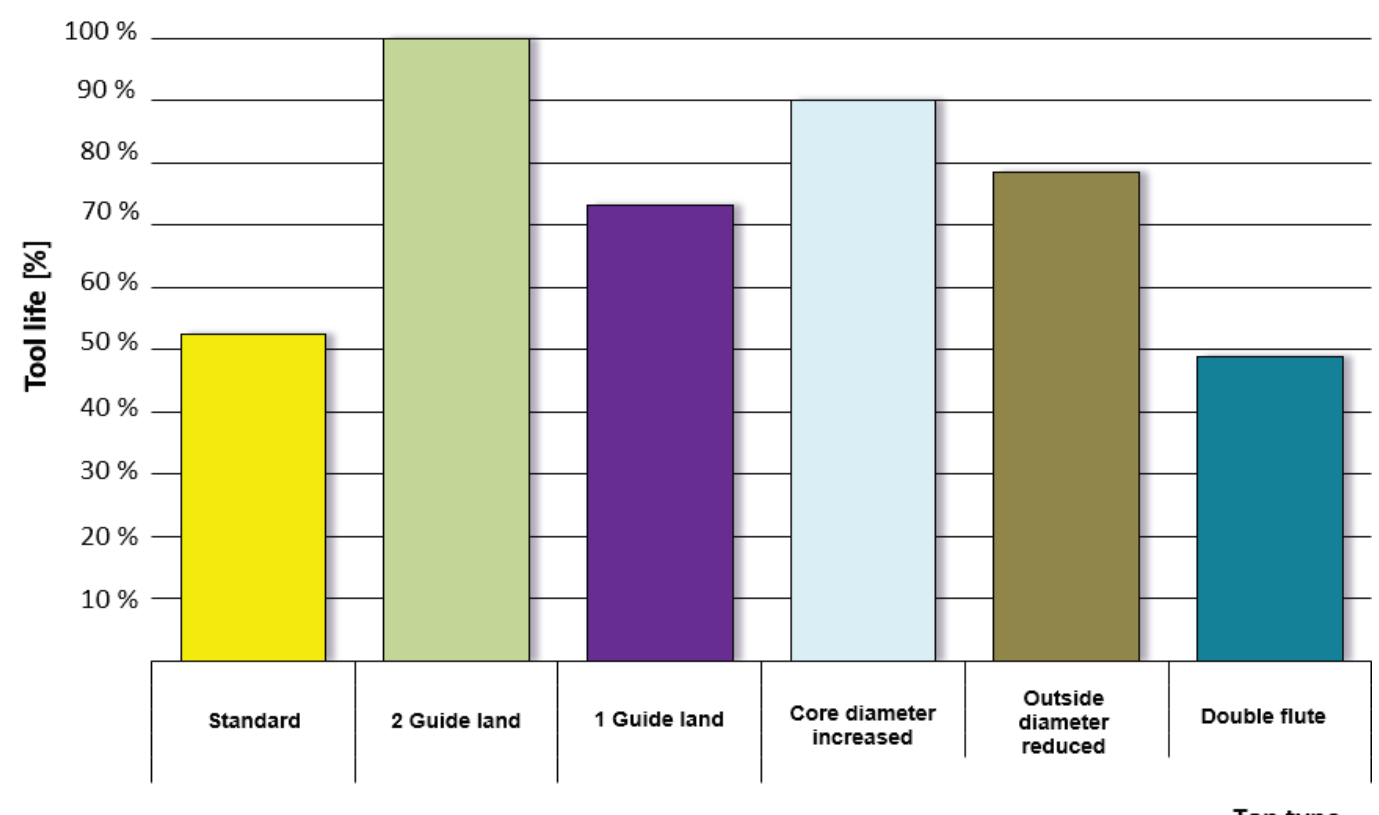

Figure 7 Tool life

Tap type 


\begin{tabular}{|c|c|c|c|c|c|c|c|c|c|c|c|c|c|c|}
\hline \multicolumn{10}{|c|}{ Table 1 Machine stopped after chip snarling } \\
\hline Tap type & $1 \%$ & $2 \%$ & $5 \%$ & $10 \%$ & $15 \%$ & $20 \%$ & $30 \%$ & $40 \%$ & $50 \%$ & $60 \%$ & $70 \%$ & $80 \%$ & $90 \%$ & $100 \%$ \\
\hline Standard & & & & & & & & & & & & & & \\
\hline 2 Guide land & & & & & & & & & & & & & & \\
\hline 1 Guide land & & & & & & & & & & & & & & \\
\hline Core diameter increased & & & & & & & & & & & & & & \\
\hline Outside diameter reduced & & & & & & & & & & & & & \\
\hline Double flute & & & & & & & & & & & & & & \\
\hline
\end{tabular}
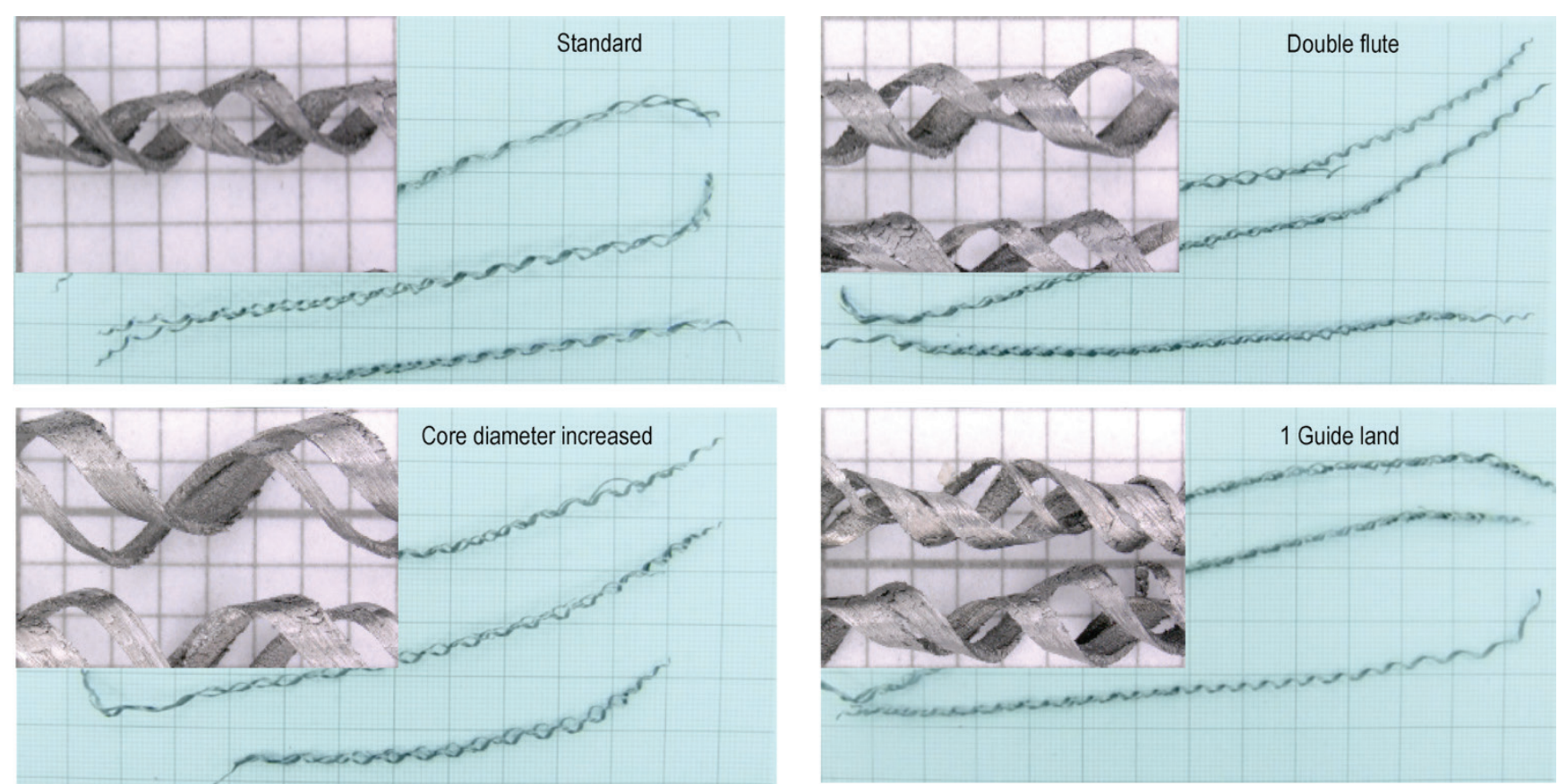

Figure 8 Chips comparison after cutting 1000 threads
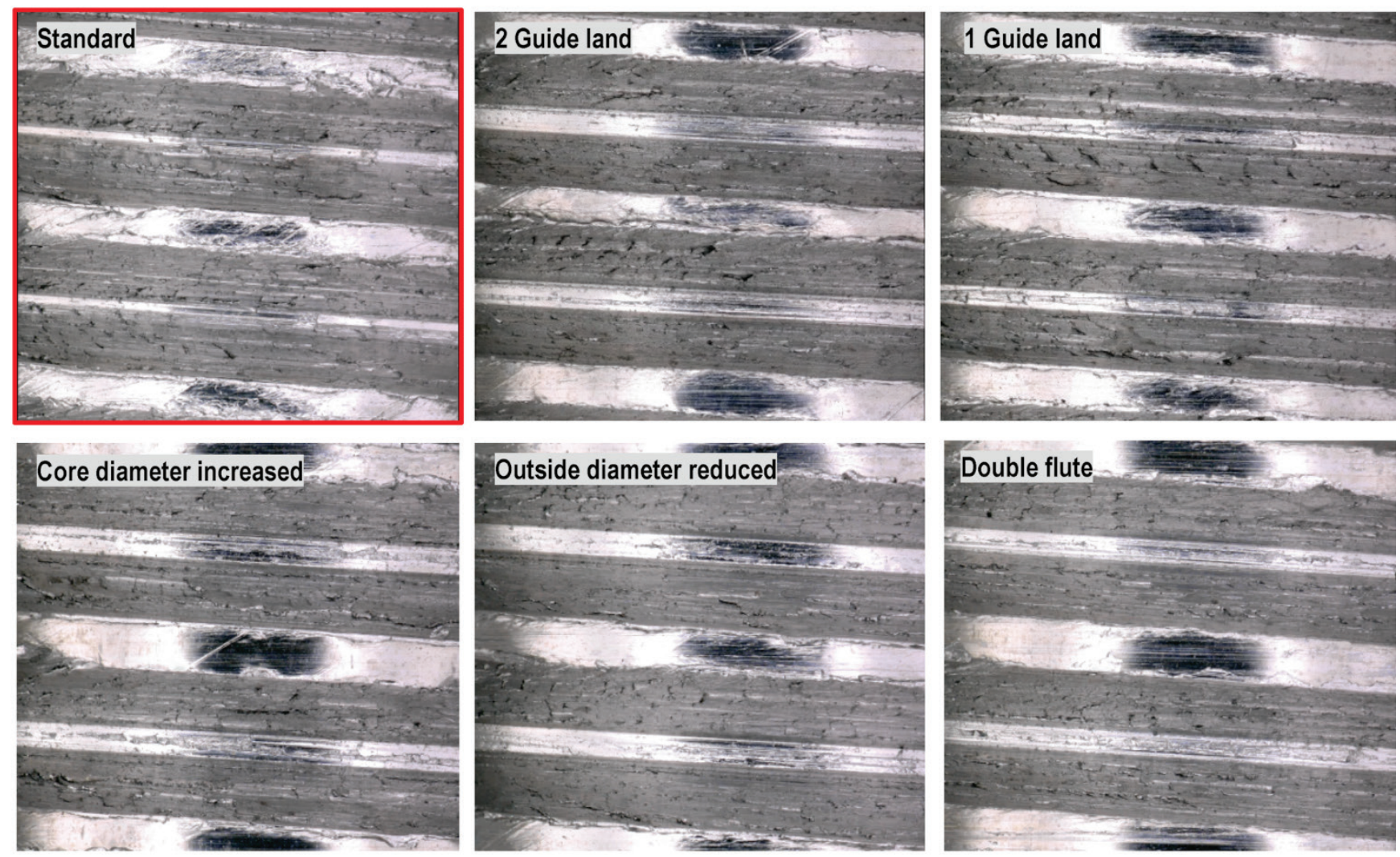

Figure 9 The surface of the threads after processing 1000 threads 


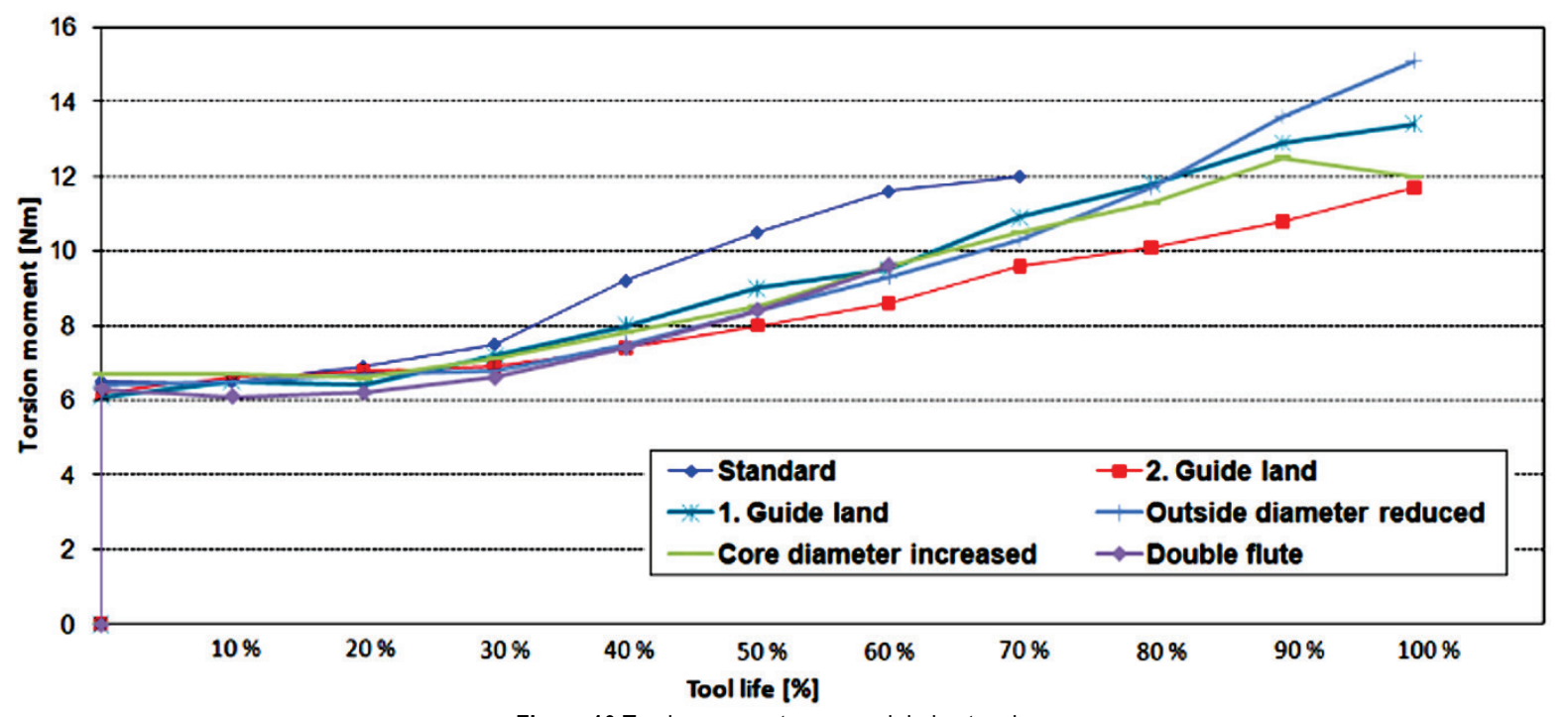

Figure 10 Torsion moment measured during tapping

\subsection{The Analysis of the Chips and Surfaces}

During testing the quality of the thread and the form of the resulted chips were analysed. Tab. 1 lists the number of interruptions during the process to remove the chips. On the tap with increased core diameter the chips rarely got stuck compared with the standard tap. It can be observed the large difference concerning the breaking of the chips between the tap with double flute and the standard tap, the first one presenting almost double breakings.

Fig. 8 shows the chips from different types of taps after processing 1000 threads. It can be seen that the chips of the tap with guide land are $20 \mathrm{~mm}$ longer and the chips of the tap with double flute are $30 \mathrm{~mm}$ longer compared with the chips of the standard tap. The length of the chips has a major influence on the tool's life. Compared with the other resulting chips after processing 1000 threads, the chips of the standard tap leave traces of deformation.

The chips resulting trough processing with the increased core diameter tap are shorter, with wider spiral compared with the chips from the other taps.

Fig. 9 shows the quality of the threads obtained after processing 1000 threads with different types.

Comparing with other threads, the surface of the thread made with the standard tap is most affected, having large deformations. The best threads are obtained with the tap with double flute and two guide lands.

\subsection{The Analysis of the Forces that Appear During Machining}

The torsion moment is measured during the cutting process throughout the testing with the aid of the Spike tool device.

The Spike tool holder is able to measure forces and torques, which occur during machining, directly at the tool where these originate. The measured data are transmitted wirelessly to a receiving data station without being disturbed by any wire [8].

The torsion moment increases constantly in time, being influenced by the wear of the tooth and chip removal. In Fig. 10 the evolution of the moment related to the tool's life is presented. The biggest moment is measured at the standard tap, and the smallest at the taps with one guide land, two guide lands and increased core diameter. The values of the torsion moment for the tap with two guide lands are the smallest and the most constant.

Fig. 11 shows the torsion moment measured after 1000 threads. Beside the fact that the moment is smaller for the tap with two guide lands, it is more constant compared to the standard tap. The vibrations that occurred during the tapping process, when using the standard tap, left traces on the surface of the thread. (see Fig. 9) That also explains the nonlinear torsion moment (see Fig. 11). The tap with two guide lands has a constant torsion moment due to the fact that it has a cylindrical diameter without external relief, offering a greater stability during the cutting process.

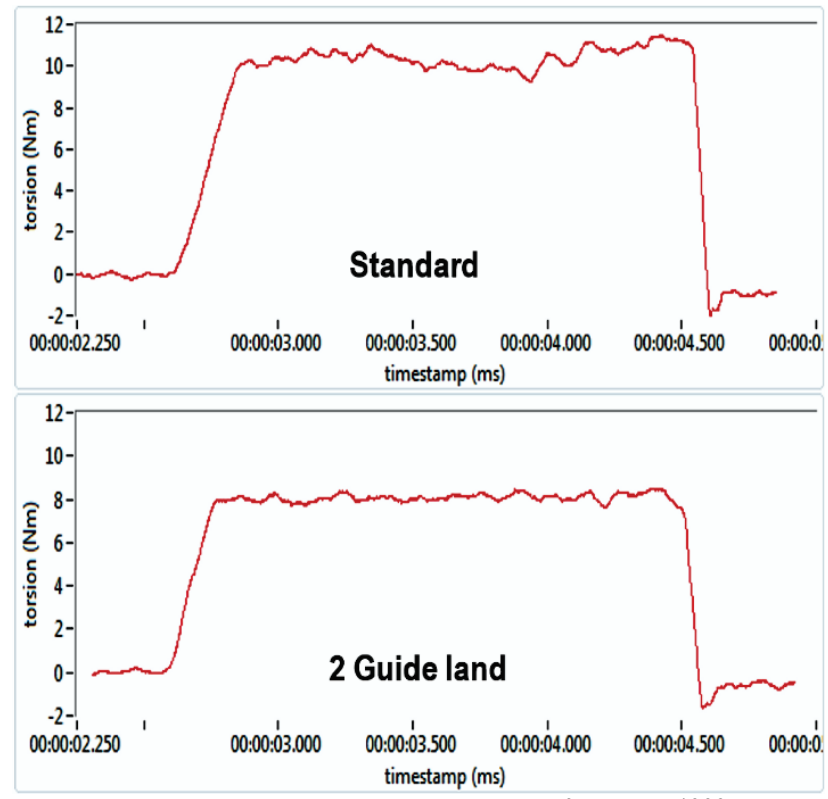

Figure 11 Torsion moment comparison measured after cutting 1000 thread holes

\section{CONCLUSION}

The purpose of this research was to produce, analyse and test 6 types of taps, with different geometries, in C45 steel processing. After analysing and testing 6 types of taps, different results were found, resulting in the best geometry for processing this material. There is a large 
difference between the tap with 2 guide land and the standard tap. The tap with 2 guide land has the best geometry for tapping C45 steel, having the smallest torsion moment during processing and the highest durability compared with the other types of taps.

The accumulation of chips is very important in the cutting process, the increased core diameter being the best compared to the geometries that made the subject of this study. This type of tap makes shorter chips because of the increasing core having minimal accumulation value. By reducing the exterior diameter related to the standard tap the tool's life increases by $20 \%$, the tap's tooth having a higher resistance to failure.

Based on the obtained results, it would be possible to research a tap with 2 guide lands having an increasing core, in order to increase durability and reliability of the cutting tool.

\section{Acknowledgements}

The authors wish to thank the Gühring Company and the Technical University of Cluj-Napoca for the support offered in preparing this article.

\section{REFERENCES}

[1] Dhar, N. R., Kamruzzaman, M., \& Ahmed, M. (2006). Effect of minimum quantity lubrication (MQL) on tool wear and surface roughness in turning AlSl-4340 steel. Journal of Materials Processing Technology, 172(2), 299-304. https://doi.org/10.1016/j.jmatprotec.2005.09.022

[2] Oosthuizen, G. A., Akdogan, G., Dimitrov D., \& Treurnicht, N. F. (2010). A review of the machinability of titanium alloys. Research and Development Journal of the South African Institution of Mechanical Engineering, 26, 43-52.

[3] LaRoux, K. G. (1988). Society of Manufacturing Engineers, 51-53.

[4] https://www.waltertools.com/SiteCollectionDocuments/ downloads/global/manuals/en-gb/handbook-drillingthreading-2009-en

[5] http://www.waltertools.com/SiteCollectionDocuments/ downloads/global/manuals/ro-ro/handbook-prototypthreading-2012-ro

[6] (2013). Messanleitung Gewindewerkzeuge, Gühring, F\&E Laiz.

[7] https://www.alicona.com/products/infinitefocus/

[8] http://www.pro-micron.de/en/products/sensory-tool-holderspike/

[9] Faur, A. S., Popa, M. S., Luca, B. C., Voina, I. D., \& Bizubac, D. (2018). Research on the influence of a new tap drill geometry on $\mathrm{C} 45,42 \mathrm{CrMo} 4$ and $\mathrm{X} 5 \mathrm{CrNi} 8$ steel processing. MATEC Web of Conferences. 178. 01002. https://doi.org/10.1051/matecconf/201817801002

\section{Contact information:}

\section{Adrian Sorin FAUR}

Technical University of Cluj-Napoca-Romania,

Manufacturing Engineering Department,

Blvd. Muncii, No. 103-105, 400641, Cluj-Napoca, Romania

E-mail: faur89@gmail.com

\section{Marcel Sabin POPA}

Technical University of Cluj-Napoca-Romania,

Manufacturing Engineering Department,

Blvd. Muncii, No. 103-105, 400641, Cluj-Napoca, Romania

E-mail:mpopa@mail.utcluj.ro

\section{Stefan SATTEL}

Gühring oHG, Head of Research and Development Department, Winterlingen Street, No. 12, 72488, Sigmaringen-Laiz, Germany E-mail: stefan.sattel@guehring.de

\section{Florin MILAS}

Technical University of Cluj-Napoca-Romania,

Manufacturing Engineering Department,

Blvd. Muncii, No. 103-105, 400641, Cluj-Napoca, Romania

E-mail: florin.milas@guehring.de 